\title{
Formale Gestaltung der Arbeit
}

\section{Schriftliche Konventionen}

Für diese Veröffentlichung wurde die aktuelle Orthografie des Deutschen verwendet. Wörter aus dem Japanischen und anderen Fremdsprachen, die Eingang in den deutschen Sprachschatz gefunden haben (z. B. „Haikai“, „Samurai“), werden in der in Nachschlagewerken des Deutschen gegebenen Schreibweise verschriftlicht.

Folgende Umschriften wurden gewählt.

Tabelle 1: Verwendete Umschriften.

\begin{tabular}{ll}
\hline Sprache & Umschrift \\
\hline Japanisch & modifizierte Hepburn-Transkription \\
\hline Chinesisch & Pinyin-Transkription \\
\hline
\end{tabular}

\section{Namenskonventionen}

Bei Nennung chinesischer und japanischer Personennamen im Fließtext wird in Entsprechung der Konvention der Familienname dem Vornamen vorangestellt. Im Literaturverzeichnis entfällt die im Fließtext wiedergegebene Attributivpartikel no の zwischen Nachnamen und Vornamen von Hofadelsfamilien (beispielsweise wird „Fujiwara no Sadaie“ im Literaturverzeichnis unter „Fujiwara, Sadaie“ verzeichnet). Ab der zweiten Erwähnung werden für Personen der Vormoderne, der seinerzeitigen Konvention folgend, nur Vorname oder Pseudonym ( $g \bar{o}$ 号) genannt. Die Namenslesung richtet sich nach der Standardform im Kokushi daijiten 国史大辞典 ([Großes Lexikon der Nationalhistorie], Yoshikawa Kōbun kan, 1979-1996).

\section{Quellenangaben}

Quellen indirekter und direkter Zitate werden in Kurzform angegeben. Die Kurzform wird im Literaturverzeichnis aufgelöst. Alle nicht mit Quellenangaben versehenen Textteile stammen vom Verfasser dieser Abhandlung. 


\section{Chinesische Originalzitate ohne Transkription}

Originalzitate aus chinesischen Klassikern werden nicht mit einer (der originalen Lautung ohnehin nicht entsprechenden) modernen Transkription versehen, sondern nur in Originalschrift gegeben.

\section{Erläuterungen zum Umschlagbild}

Das Umschlagbild zeigt den Eintrag zum sinojapanischen Wort kyojitsu 虚実 aus dem populären enzyklopädischen Lexikon Dai kōeki shinkaisei Dai Nippon eitai setsuyō mujinzō Shinsō ryōten 大広益新改正大日本永代節用無尽蔵真草両点 (1849). Rechts der kalligrafischen „Kurrentschrift“ wird die neutrale Standardlesung kyojitsu gegeben. Dagegen finden sich seitlich der etwas kleineren „Blockschrift“Version interpretierende Lesungen. Das neutrale kyo 虚 wird nun rechts mit „Leere“ (munashi ムナシ), links mit „Lüge“ (uso ウソ) übersetzt, das neutrale jitsu 実 rechts mit „Fülle“ (miteri ミテリ), links mit „Wahrheit“ (makoto マコト). Je nach Zusammenhang werden in kyojitsu demnach Abstraktes und Konkretes, Metaphysisches und Physisches oder gar Lüge und Wahrheit einander gegenübergestellt. Das Lexikon verdichtet in seinen Angaben in bemerkenswerter Intensitität die Vieldeutigkeit des Wortes, welches in der literaturtheoretischen Diskussion der Jahre 1850 bis 1890 häufig zur wertneutralen oder polemischen Analyse des Bezugs der Literatur zur außerliterarischen Wirklichkeit verwendet und dabei in seinem Begriffsgehalt immer weiter ausdifferenziert wird. 